\title{
Influence of Tooth Size on Crowding in Assamese (North-East Indian) Population- A Biometric Study
}

\author{
H. Chokotiya ${ }^{1}$, M. Bora ${ }^{2}$, N. Baruah ${ }^{3}$, S. Shrivastava ${ }^{4}$, S. Sonwane ${ }^{5}$, A.S. Parate $^{6}$
}

\begin{abstract}
${ }^{1}$ Department of Dentistry, NSCB Medical College, Jabalpur, Madhya Pradesh, India. ${ }^{2}$ Department of Orthodontics, Regional Dental College, Guwahati, Assam, India. ${ }^{3}$ Department of Orthodontics, Regional Dental College, Guwahati, Assam, India. ${ }^{4}$ Department of Orthodontics, Mansarovar Dental College, Bhopal, Madhya Pradesh, India. ${ }^{5}$ Department of Orthodontics, Mansarovar Dental College, Bhopal, Madhya Pradesh, India. ${ }^{6}$ Department of Dentistry, Government

Medical College, Shahdol, Madhya Pradesh, India.
\end{abstract}

\section{ABSTRACT}

\section{BACKGROUND}

A disparity in the relationship between jaw size and tooth size which results in impacted, rotated or ectopic teeth is defined as dental crowding. Conditions like excessively small bony bases of the jaws, excessively large teeth and a combination of large teeth and small jaws may predispose the dental arches to crowding. We wanted to compare and evaluate individual mesiodistal (MD) tooth sizes in permanent dentition with moderate, mild and no crowding.

\section{METHODS}

The present study was conducted on maxillary and mandibular study models of 90 Assamese subjects in the age group of 12-18 years. Subjects were divided into three equal test groups with group I having no crowding (zero discrepancy), group II with mild crowding ( 0.1 to $5 \mathrm{~mm}$ of discrepancy),) and group III with moderate crowding (5.1 mm or more of discrepancy). Mesiodistal widths of each tooth from first molar to opposite first molar were measured at the largest mesiodistal dimension using a digital vernier caliper and arch perimeter is measured with brass wire. ANOVA was used to compare mean values among more than two independent groups.

\section{RESULTS}

Evaluation is done for mean, standard deviation and statistical significance of mesiodistal tooth size values for each of the groups. To analyse the data, ANOVA test was used, and the level of significance was at 0.05 . Mesiodistal tooth size of the maxillary and mandibular $2^{\text {nd }}$ premolar, maxillary lateral incisors had statistically significant difference in the three groups of crowding $(\mathrm{p}<0.05)$.

\section{CONCLUSIONS}

The mesiodistal tooth size of maxillary and mandibular $2^{\text {nd }}$ premolar, maxillary lateral incisors are largely responsible for the variation that is seen in the dental crowding in the Assamese population.

\section{KEY WORDS}

Arch Perimeter, Crowding, Mesiodistal (MD) Tooth Size, Study Models
Corresponding Author: Dr. Heeralal Chokotiya, Senior Resident, Department of Dentistry, NSCB Medical College, Jabalpur, Madhya Pradesh, India. E-mail: drheeralalchokotiya@ymail.com

DOI: $10.14260 / j e m d s / 2019 / 728$

Financial or Other Competing Interests: None.

How to Cite This Article:

Chokotiya H, Bora M, Baruah N, et al. Influence of tooth size on crowding in Assamese (North-East Indian) populationa biometric study. J. Evolution Med. Dent. Sci. 2019;8(44):3357-3361, DOI: 10.14260/jemds/2019/728

Submission 30-07-2019, Peer Review 20-10-2019, Acceptance 26-10-2019, Published 04-11-2019. 


\section{BACKGROUND}

The mesiodistal (MD) crown dimension, which includes crown size, tooth size also referred to as crown length provide significant information on human biological problems and evolution as well as on orthodontic and forensic dentistry. A discrepancy between jaw and tooth size which results in impacted teeth, rotated, or ectopic is defined as dental crowding. ${ }^{1}$ The conditions like excessively small bony bases of the jaws, excessively large teeth and a combination of large teeth and small jaws may predispose the dental arches to crowding. According to Nance, ${ }^{2}$ the difference between the space needed in the dental arch and the space available in that arch is defined as dental crowding. The dental crowding or spacing can be described as an expression of an altered tooth/ tissue ratio or as a dentoalveolar disproportion. Dental crowding has been present since prehistoric time as observed by Mockers and Coworkers. ${ }^{3}$ The prevalence of dental crowding according to the latest National Health and Nutrition Examination Survey (NHANES III) ${ }^{4}$ is as follows, almost half of children with mild dental crowding is in mixed dentition, about one-third of the population with moderate crowding ( $4 \mathrm{~mm}$ or more) and $15 \%$ population with severe crowding.

For aesthetic reasons it is logical that the most common complaint of patients seeking orthodontic treatment is to straighten their crooked teeth. ${ }^{5}$ The other unaesthetic issues are incompetent lips, profile problems, soft tissue, poor gingival contours leading to gingivitis of tissues and dental protrusion. For correct Orthodontic diagnosis and treatment planning the accurate assessment of dental crowding and the space required to alleviate this malocclusion is critical. The objective of orthodontic treatment is to provide good occlusal relationship, optimum soft tissue profile and stability of results without any relapse.

According to Hooton ${ }^{6}$ evolutionary trend towards reduced jaw size is predisposing factor for dental crowding. Brash $^{7}$ said that inter breeding in ethnic groups which were physically dissimilar resulted in crowding. Barber ${ }^{8}$ suggested that crowding resulted from abnormal muscle activity and abnormal tooth position. Moore, Lavelle, and Spences ${ }^{9}$ stressed upon environmental dominance (eg, soft diet and loss of arch length caused by caries) over genetic factors, especially when ethnic groups were compared.

Odontometry is the anthropologic science of measuring the size and proportion of teeth (Peck \& peck). ${ }^{10}$ It is used to elucidate some aspects of the phylogeny and ontogeny of human's dentition. ${ }^{11}$ The mesiodistal tooth size provide significant information on human evolution and biological problems as well as forensic and clinical dentistry. In forensic odontology tooth size proved to be a reliable sex discriminator. Arch length and arch perimeter are two different entities, ${ }^{12}$ which are often misused to denote each other. While arch perimeter is measured as a geometrical dental arc, formed by the teeth at their incisal/ cuspal edges, arch length is the one which denotes basal perimeter on the skeletal bases, where the teeth should be placed in normal alignment.

Although many investigators have examined the relationship of arch size and tooth size with crowding, but the observations made in these studies are quite different from each other, hence questionable. It is not justified to use the norms obtained from these studies to all human population irrespective of geographical and genetic variation, nutritional status and growth and development. Various studies have compared the mesiodistal tooth size between dental arches with spacing and crowding in some specific ethnic group, so far, no such studies have been done on the Assamese population. Thus, the present study was undertaken to determine the effects of mesiodistal tooth size on crowding in Assamese (North -East Indian) population. We wanted to compare individual mesiodistal (MD) tooth sizes in permanent dentition with moderate, mild and no crowding and evaluate the effect of mesiodistal (MD) tooth sizes on dental crowding.

\section{METHODS}

This cross-sectional study was conducted at department of Orthodontic. Prior to commencement of treatment, informed consent was obtained from patients and/or parents that their records might be used for research purpose. The process of acquiring relevant data for the study began after its Ethical approval by Institution. The present study was conducted on maxillary and mandibular models of 90 Assamese subjects were of age group from 12 to 18 years. A sample size of 90 was selected by convenience sampling. The subjects were randomly selected from the patients seeking Orthodontic treatment in the Department of Orthodontics, Government Dental College and from local schools. Subjects included in our study had a complete set of permanent dentition from $1^{\text {st }}$ to opposite $1^{\text {st }}$ permanent molar with an age range of 12-18 year because early adult dentitions have less mutilation and minimum attrition in proximal surface in greater number of subjects, none of the subject had previous history of orthodontics treatment and the subjects are of Assamese ethnicity, residing in Assam, which was confirmed from family history.

Subject with missing, impacted, broken, grossly carious teeth or showing other dental abnormalities were excluded from the study. Alginate impressions were taken on standard stock trays and the cast were immediately poured after the impression making. The largest mesiodistal measurement from the anatomic mesial contact point to the anatomic distal contact point was taken to the nearest $0.1 \mathrm{~mm}$ by means of pointed digital vernier calliper. The digital vernier calliper was placed from the buccal surface keeping it parallel to the occlusal plane (Figure 1 and 2).

Arch perimeter ${ }^{12,13}$ is measured by a brass wire with the wire placed from distal contact point of right first molar to centres of the contact areas of the teeth in the buccal segments and along the incisal edges of the anterior teeth and wire is continued up to the same position to the left molar on the opposite side (Figure 3). The first measurements done were the mesiodistal width of first molar, second premolar, first premolar, canine, lateral incisor and central incisor from right first molar to left first molar in each arch and in the same way second measurements were taken. Here the first measurement should not bias the second. If the measurements differ by more than $0.2 \mathrm{~mm}$ the tooth was remeasured, and a third measurement was done and registered. If the measurements differ by less than $0.2 \mathrm{~mm}$, the first measurement was registered. The data collected was 
analysed statistically. All the measurements were repeated after 15 days by the same operator. To determine measurement error, Dahlberg's formula was used-14,15

Standard error $=\sqrt{ } \sum \mathrm{sd} 2 / 2 \mathrm{n}$

Crowding is defined as the difference in millimetres between the arch perimeter and the mesiodistal tooth size sum. Each dental arch has been classified (Figure-4) as three, Group-I: No crowding (zero discrepancy), this test groups contained 30 subjects. Group-II: Mild crowding ( 0.1 to $5 \mathrm{~mm}$ of discrepancy), this test groups contained 30 subjects. Group-III: Moderate crowding $(5.1 \mathrm{~mm}$ or more of discrepancy), this test groups contained 30 subjects. The results were then statistically evaluated. A level of significance $(P \leq 0.05)$ was used for the statistical tests.

\section{Statistical Analysis}

The different measurements were collected from the dental study models and subjected to the following statistical analysis. Statistical analysis was done using SAS 9.3 software and the tables and graphs were prepared using MS Excel 2007. Analysis of variance (ANOVA) is indicated to compare mean values among more than two independent groups. Since in the present study mean mesiodistal, was compared among three groups, use of ANOVA to determine statistical significance has been justified. The analysis of variance statistic computed as ' $F$ ' indicates whether any of the means are significantly different from each other, but it does not indicate which pair of means differ. This test was followed by Duncan multiple range test and Scheffe's multiple comparison procedure to assess the intergroup significance of the mesiodistal tooth size was compared among three groups.

\section{RESULTS}

\begin{tabular}{|c|c|c|c|}
\hline \multirow{2}{*}{$\begin{array}{l}\text { Mesiodistal } \\
\text { Tooth Dimension } \\
\text { (mm) }\end{array}$} & \multicolumn{3}{|c|}{ Lower Arch (Mandibular Arch) } \\
\hline & $\begin{array}{c}\text { No Crowding } \\
(\mathrm{n}=30) \text { Mean } \pm \mathrm{SD}\end{array}$ & \multirow{2}{*}{\begin{tabular}{|c|}
$\begin{array}{c}\text { Mild Crowding } \\
(\mathbf{n}=30) \\
\text { Mean } \pm \text { SD }\end{array}$ \\
$10.93^{\mathrm{a}} \pm 0.16$
\end{tabular}} & \multirow{2}{*}{$\begin{array}{c}\begin{array}{c}\text { Moderate Crowding } \\
\text { (n=30) Mean } \pm \text { SD }\end{array} \\
11.21^{a} \pm 0.11\end{array}$} \\
\hline $1^{\text {st }}$ Molar & $10.94 \mathrm{a} \pm 0.13$ & & \\
\hline $2^{\text {nd }}$ Premolar & $6.97 \mathrm{~b} \pm 0.07$ & $7.11 \mathrm{ab} \pm 0.08$ & $7.28 \mathrm{a} \pm 0.08$ \\
\hline 1st Premolar & $7.14 \mathrm{~b} \pm 0.08$ & $7.23 b \pm 0.08$ & $7.46 \mathrm{a} \pm 0.08$ \\
\hline Canine & $6.99 \mathrm{~b} \pm 0.09$ & 6.97 & $7.23 \mathrm{a} \pm 0.08$ \\
\hline Lateral incisor & $6.22 \mathrm{a} \pm 0.08$ & $6.21 \mathrm{a} \pm 0.07$ & $6.41^{\mathrm{a}} \pm 0.08$ \\
\hline Central incisor & $5.56^{\mathrm{a}} \pm 0.06$ & $5.65^{\mathrm{a}} \pm 0.06$ & $5.75^{\mathrm{a}} \pm 0.07$ \\
\hline \multicolumn{4}{|c|}{$\begin{array}{l}\text { Table 1. Comparison of Individual Mesiodistal Tooth Dimension } \\
\text { between No, Mild and Moderate Crowding in Mandibular Arches }\end{array}$} \\
\hline & & & \\
\hline
\end{tabular}

\begin{tabular}{|c|c|c|c|}
\hline $\begin{array}{c}\text { Mesiodistal } \\
\text { Tooth dimension } \\
(\mathbf{m m})\end{array}$ & \multicolumn{3}{|c|}{ Upper Arch (Maxillary Arch) } \\
\cline { 2 - 4 } & $\begin{array}{c}\text { No Crowding } \\
(\mathbf{n}=\mathbf{3 0}) \text { Mean } \pm \text { SD }\end{array}$ & $\begin{array}{c}\text { Mild Crowding } \\
(\mathbf{n}=\mathbf{3 0}) \text { Mean } \pm \text { SD }\end{array}$ & $\begin{array}{c}\text { Moderate Crowding } \\
(\mathbf{n}=30)\end{array}$ \\
\hline $1^{\text {st }}$ Molar & $9.99^{\mathrm{b}} \pm 0.10$ & $10.21^{\mathrm{b}} \pm 0.11$ & $10.50^{\mathrm{a}} \pm 0.06$ \\
\hline $2^{\text {nd }}$ Premolar & $6.59^{\mathrm{b}} \pm 0.08$ & $6.78^{\mathrm{ab}} \pm 0.09$ & $7.02^{\mathrm{a}} \pm 0.08$ \\
\hline $1^{\text {st }}$ Premolar & $7.06^{\mathrm{a}} \pm 0.09$ & $7.18^{\mathrm{a}} \pm 0.07$ & $7.20^{\mathrm{a}} \pm 0.08$ \\
\hline Canine & $7.85^{\mathrm{a}} \pm 0.09$ & $7.96^{\mathrm{a}} \pm 0.08$ & $8.06^{\mathrm{a}} \pm 0.07$ \\
\hline Lateral incisor & $7.02^{\mathrm{b}} \pm 0.12$ & $7.30^{\mathrm{ab}} \pm 0.08$ & $7.42^{\mathrm{a}} \pm 0.11$ \\
\hline Central incisor & $8.90^{\mathrm{a}} \pm 0.12$ & $8.66^{\mathrm{a}} \pm 0.08$ & $8.91^{\mathrm{a}} \pm 0.10$ \\
\hline Table 2. Comparisons of the Individual Mesiodistal Tooth Dimension \\
between No, Mild and Moderate Crowding in Maxillary Arches
\end{tabular}
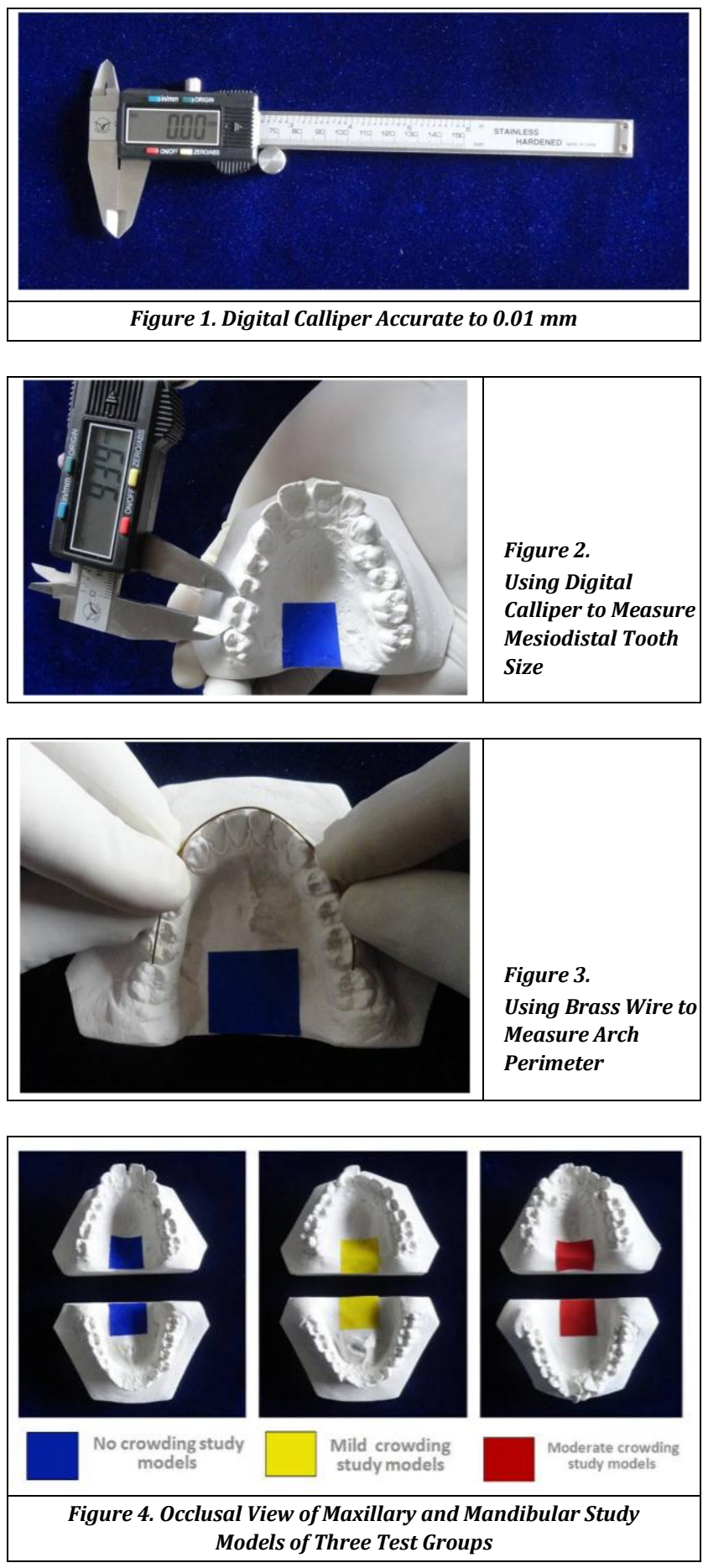

The mesiodistal dimension of the mandibular and maxillary $2^{\text {nd }}$ premolar, maxillary lateral incisors had statistically significant difference in three groups of crowding $(\mathrm{p}<0.05)$ but maxillary $1^{\text {st }}$ molar, mandibular $1^{\text {st }}$ premolar and canines had statistically significant difference in correlation with only no crowding and moderate crowding groups $(\mathrm{p}<0.05)$ The mesiodistal dimension of the mandibular $1^{\text {st }}$ molar, mandibular and maxillary central incisor, maxillary $1^{\text {st }}$ premolar and mandibular lateral incisor had no influence on the dental crowding as they did not show any statistically significant difference in all the groups of crowding ( $p>0.05)$. 


\section{DISCUSSION}

The findings of present study are similar to the result obtained in the previous studies. ${ }^{16,17}$ This shows that the mandibular and maxillary $2^{\text {nd }}$ premolar and maxillary lateral incisor's mesiodistal tooth dimensions are most important factor for tooth size and arch length discrepancy in Assamese population.

Norderval et al. (1975) ${ }^{18}$ demonstrated mandibular crowding due to larger dimension of incisors. These findings are similar to the results obtained in the present study as mesiodistal tooth dimension is larger in moderate crowding group as compared to no crowding group. Lavelle and Foster, ${ }^{19}$ Fastlicht, ${ }^{20}$ and Foster and associates ${ }^{21}$ reported sexual dimorphism in crowding which investigated less dental crowding in males than in females. Presently separate measurements were not done for females and males. Doris JM et $\mathrm{al}^{22}$ demonstrated to compare mesiodistal tooth dimension between a group of patients with crowded dental arches and group of patients with ideal occlusion in differ sex. There was concluded that less correlation between the the status of the tooth alignment in dental arches with crowding on differ sex. Present study is in accordance with the above study.

Fastlicht ${ }^{20}$ Lundstrom, ${ }^{23}$ and Doris et $\mathrm{al}^{22}$ conducted a study to conclude whether the average values of mesiodistal tooth size was significantly higher in crowded arches compared with the good tooth alignment group. This finding led to the conclusion that lower crown dimensions are associated with less or no crowding than with crowded arches. The findings of above studies similar to the result obtained in the present study for degree of crowding in relation to mesiodistal tooth dimension of central incisors, $1^{\text {st }}$ and $2^{\text {nd }}$ premolar in mandibular arch and lateral incisor, canine, $1^{\text {st }}$ premolar, $2^{\text {nd }}$ premolar and $1^{\text {st }}$ molar in maxillary arch. Mills LF (1964) ${ }^{24}$ conducted a study to conclude the incisor crown diameter also did not vary in persons with and without malalignment. The findings of above study are similar to the result obtained in the present study. The mesiodistal diameter of incisor crown also did not vary in mandibular central and lateral incisor, maxillary central incisor in three group of crowding in the Assamese population because they did not have statistically significant difference in three groups of crowding ( $p>0.05)$.

The maxillary canines had minor morphologically variation in the mild, moderate and severe crowding ( $p>0.05$, table 2) was found in the present study in accordance with the studies of Lundstrom ${ }^{23}$ and Horowitz et al. ${ }^{25}$ As these teeth occupy strategic locations in the dental arch, connecting the incisor series with premolar series, comparatively little genetic component of variability in the canines can be related to function. Dahlberg, ${ }^{26}$ also supported this finding and considered the canine morphologically stable.

Doris et al suggested that the best sample for tooth size measurements can be provided from early permanent dentitions because early adulthood dentitions has minimum attrition in proximal surface and minimum mutilation. Present study is in accordance with the age range of the subjects between 12 to 18 years or early adulthood." Coleman et $\mathrm{al}^{27}$ and Miller ${ }^{28}$ investigated the question of the accuracy of plaster casts made from alginate impressions as a representation of the actual mesiodistal tooth width. The results said that when poured immediately, alginate impressions produce the most accurate dental casts. Present study is in accordance with the above method. As soaped models may affect the tooth size measurements, presently all the measurements were taken directly on non-soaped dental casts. Hunter and Priest ${ }^{29}$ studied that soaped models are slightly larger in over-all dimension and measurements taken from non-soaped dental casts are more consistent and accurate.

Rhee $\mathrm{SH}$ et $\mathrm{al},{ }^{30}$ reported racial bias in mesiodistal tooth size and this study evaluated tooth diameters and arch perimeters in black and white populations. The black population sample's canine, first and second premolar, and first molar's mesiodistal diameters were significantly larger than those of the white population sample. No significant differences were found in the mean mesiodistal diameters of incisors between the two groups. The findings of above study are similar to the result obtained in the present study for mesiodistal tooth size in upper and lower arch (Table 1, 2) in relation to mesiodistal tooth size of central incisor which did not differ significantly in three group of crowding.

\section{CONCLUSIONS}

Mandibular and maxillary $2^{\text {nd }}$ premolar and maxillary lateral incisor's mesiodistal tooth dimensions are the most important factors for tooth size and arch length discrepancy in Assamese population. The mesiodistal tooth dimension of the mandibular $1^{\text {st }}$ molar, mandibular and maxillary central incisors, maxillary $1^{\text {st }}$ premolar and mandibular lateral incisor had no influence on the dental crowding.

\section{REFERENCES}

[1] Howe RP, McNamara JA Jr, O'Connor KA. An examination of dental crowding and its relationship to tooth size and arch dimension. Am J Orthod 1983;83(5):363-73.

[2] Nance HN. The limitations of orthodontic treatment: mixed dentition diagnosis and treatment. Am J Orthod 1947;33(4):177-223.

[3] Mockers 0, Aubry M, Mafart B. Dental crowding in prehistoric population. European Journal of Orthodontics 2004;26(2):151-6.

[4] Brunelle JA, Bhat M, Lipton JA. Prevalence and distribution of selected occlusal characteristics in the US population, 1988-1991. J Dent Res 1996;75 Spec No: 706-13.

[5] Svedstrom-Oristo AL, Terttu P, Pietila I, et al. Acceptability in dental appearance in a group of finnish 16-to-25-year olds. Angle Orthod 2009;79(3):479-83.

[6] Hooton EA. Up from the ape. Revised edn. New York: The Macmillan Company, 1947.

[7] Brash JC. The aetiology of irregularity and malocclusion of the teeth. $2^{\text {nd }}$ edn. London: Dental Board of the United Kingdom 1956.

[8] Barber TK. The crowded arch. J South Calif Dent Assoc 1967;35(5):232-40. 
[9] Moore WJ, Lavelle CLB, Spence TF. Changes in the size and shape of the human mandible in Britain. Br Dent J 1968;125(4):163-9.

[10] Peck H, Peck S. An index for assessing tooth shape deviations as applied to the mandibular incisors. Am J Orthod 1972;61(4):384-401.

[11] Hattab FN, Al-Momani AS, Yassin OM, et al. Crown diameters of deciduous teeth in Jordanians. Dental Anthropology 1999;13(2):1-8.

[12] Kharbanda OP. Diagnosis and management of Malocclusion and Dentofacial Deformities. $1^{\text {st }}$ edn. Elsevier Publication 2009: p. 128-30.

[13] Johal AS, Battagel JM. Dental crowding: a comparison of three methods of assessment. Eur J Orthod 1997;19(5):543-51.

[14] Dahlberg G. Statistical methods for medical and biological students. New York: Interscience Publications 1940.

[15] Houston WJB. The analysis of errors in orthodontic measurements. Am J Orthod 1983;83(5):382-90.

[16] Bernabe E, Flores-Mir C. Dental morphology and crowding: a multivariate approach. Angle Orthod 2006;76(1):20-5.

[17] Puri N, Pradhan KL, Chandna A, et al. Biometric study of tooth size in normal, crowded and spaced permanent dentitions. Am J Orthod Dentofacial Orthop 2007;132(3):279.e7-e14.

[18] Norderval K, Wisth PJ, Boe OE. Mandibular anterior crowding in relation to tooth size and craniofacial morphology. Scand J Dent Res 1975;83(5):267-73.
[19] LaVelle CL, Foster TD. Crowding and spacing of the teeth in an adult British population. Dent Pract Dent Rec 1969;19(7):239-42.

[20] Fastlicht J. Crowding of mandibular incisors. Am J Orthod 1970;58(2):156-63.

[21] Foster TD, Hamilton MC, Lavelle CL. A study of dental arch crowding in four age-groups. Dent Pract Dent Rec 1970;21(1):9-12.

[22] Doris JM, Bernard BW, Kuftinec MM, et al. A biometric study of tooth size and dental crowding. Am J Orthod 1981;79(3):326-36.

[23] Lundstrom A. Changes in crowding and spacing of the teeth with age. Dent Pract Dent Rec 1969;19(6):218-24.

[24] Mills LF. Arch width, arch length and tooth size in young adult males. Angle Orthod 1964;34(2):124-9.

[25] Horowitz SL, Osborne RH, De George FV. Hereditary factors in tooth dimensions: a study of anterior teeth in twins. Angle Orthod 1958;28(2):87-93.

[26] Dahlberg AA. The changing dentition of man. J Am Dent Assoc 1945;32(11):676-90.

[27] Coleman RM, Hembree JH Jr, Weber FN. Dimensional stability of irreversible hydrocolloid impression material. Am J Orthod 1979;75(4):438-46.

[28] Miller MW. Syneresis of alginate impression materials. Br Dent J 1975;139(11):425-30.

[29] Hunter WS, Priest WR. Errors and discrepancies in measurement of tooth size. J Dent Res 1960;39:405-14.

[30] Rhee SH, Nahm DS. Triangular-shaped incisor crowns and crowding. Am J Orthod Dentofacial Orthop 2000;118(6):624-8. 